\title{
Editorial: Coping with the future
}

\section{Richard Ennals}

\section{Introduction}

The European Journal of Workplace Innovation (EJWI) was launched as part of a wider initiative. It is intended to enable researchers and practitioners to sketch future directions in advance of calls for proposals. It stimulates continued organic collaboration in the wider network associated with the European Workplace Innovation Network (EUWIN). It is thus in part an outcome of EUWIN, with which it shares a common ancestry. EJWI can add value to project-based development work, offering free, online, open access. The scale of operations could be scaled up in advance of a return to major consistent funding. Importantly, it is a practical implementation of the idea of a "Penny University", engaging a wider community in open access learning and debate.

European Commission project officers are valued network partners, rather than simply sources of funding. Several Directorates-General support a range of networks, with overlapping membership. Partner journals such as the International Journal of Action Research (IJAR) and EJWI are also networks, with global reach, including North and South America, Africa, and Asia. The movement can work through conferences based on networks, which can support increasing virtual participation. Publishers can be potential long-term partners. The roles of universities can be redefined, for example as hosts for regional development coalitions.

Researchers and practitioners need to maintain network connections, regardless of developments such as Brexit. Groups from Norway and UK seek to remain associated with EU 
colleagues and programmes. EJWI can highlight similar objectives of research communities with different starting points. It can enable processes of dialogue and social benchmarking, as a core of researchers have experience of working across borders. As with the proposal for a European Lifelong Learning Network (TRIPOD) in 2003, EJWI and EUWIN can build on existing networks, supporting processes of bottom up continuous improvement.

There are European themes which cut across DGs and national programmes, which can be addressed in EJWI, such as Workplace Innovation, Lifelong Learning, Regional Development, the European Social Pillar, Ageing Workers (including ageing researchers), and Succession Planning beyond the Horizon. In summary, as Björn Gustavsen and I argued in 1999, Europe is a "Development Coalition". We continue to show that much can be done with finite resources.

\section{Articles}

In EJWI 3.2, We publish four new articles, focused around Industry 4.0 and Workplace Innovation, which demonstrate the continuing vitality of the field. We can see the development of central debates based on the emerging literature of Workplace Innovation, including earlier issues of EJWI.

Papke and Wagner discuss how approaches to Agile organisations can make practical and effective use of project management methods, such as Scrum, to deliver objectives of Workplace Innovation.

Mühlbradt and Kuyhlang introduce Industrial Cognitive Engineering (ICE), which brings together Workplace Innovation and Systems Thinking, drawing on a wider research tradition and an international network.

Lied outlines how Leadership and Improvement are vital issues for Trade Unions in the context of Lean Manufacturing. This extends the debate beyond company management, and draws on the distinctive legacy of the Nordic model.

Totterdill, one of the co-ordinators of EUWIN, considers Corporate Responses to Industry 4.0. He warns of the dangers of successive management fads, and presents a fresh motivational account of "The Essential Fifth Element", which integrates and adds value to Innovative Work Practices. The article includes extensive references to the literature.

\section{Reviews}

EJWI 3.2 includes my reviews of three books.

Workplace Innovation: Theory, Research and Practice (eds. Oeij, Rus and Pot; Springer 2017) brings together the work of leading researchers. It is full of insightful overviews, with few detailed cases. There is some rhetoric, and repetition of key themes such as "The Essential Fifth Element". A movement has been developed, which has continued beyond the end of EU funding. We could see Workplace Innovation in terms of "family resemblances" between diverse cases, rather than necessarily sharing a common essence. 
Learning Factories: The Nordic Model of Manufacturing (Holtskog, Carayannis, Kaloudis and Ringen; Palgrave 2018) deals with a successful and interesting set of cases, with a focus on automobile manufacturing, where innovation is vital for survival in a global competitive market. The context of the Norwegian national $\mathrm{PhD}$ programme in Enterprise Development and Working Life (EDWOR) is interesting, but hard to generalise across Europe. The Raufoss regional phenomenon is unique and instructive, with echoes of Silicon Valley in California.

Microcosmographia Academica: Being a Guide for the Young Academic Politician (Cornford; Bowes \& Bowes 1908) reminds us that these issues are not entirely new. The leading researchers in the field were "Young Men in a Hurry". They are now older, but still impatient.

A fourth book was published in April 2018, in hardback and paperback. Coping with the Future: Rethinking Assumptions for Society, Business and Work (eds. Johnsen, Holtskog and Ennals; Routledge 2018) recognises that we do not know what will happen in the future, and considers the role of social science. Using a central discussion of "Kodak Moments", involving transformative and disruptive change, this collaboratively written book opens up new debates which go beyond the Nordic context. The resulting discourse exemplifies the Nordic model, and offers an approach to society, business and work after the financial crises which exposed key weaknesses in liberal capitalism.

\section{Conferences}

In our planning to date for the Coping with the Future conference at the University of Agder $8^{\text {th }}-10^{\text {th }}$ October 2018, we have built on a long-standing culture of dialogue, in which IJAR, EUWIN and EJWI have played roles. Our conference is led by EUWIN on $8^{\text {th }}$ October, with a focus on business; by EJWI on $9^{\text {th }}$ October, with a call for papers from researchers and practitioners; and IJAR on $10^{\text {th }}$ October, with invited speakers on the future of social science. The conference organiser is Professor Hans Christian Garmann Johnsen of the University of Agder, who is managing editor of EJWI.

We also provide details of two further conferences, EURAM in June 2018, and IWOT22 in September 2018 